Article

\title{
Microwave-Assisted Transesterification of Macroalgae
}

\author{
Angeles Cancela ${ }^{1}$, Rocio Maceiras ${ }^{2, *}$, Santiago Urrejola ${ }^{2}$ and Angel Sanchez ${ }^{1}$ \\ 1 Chemical Engineering Department, ETSEI, Rua Maxwell s/n, University of Vigo, \\ Campus Lagoas-Marcosende, 37210 Vigo, Spain; E-Mails: chiqui@uvigo.es (A.C.); \\ asanchea@uvigo.es (A.S.) \\ 2 Defense University Center, Escuela Naval Militar, Plaza de España 2, 36920 Marin, Spain; \\ E-Mail: urrejola@cud.uvigo.es \\ * Author to whom correspondence should be addressed; E-Mail: rmaceiras@uvigo.es; \\ Tel.: +34-986-804-933; Fax: +34-986-804-929.
}

Received: 22 February 2012; in revised form: 19 March 2012 / Accepted: 22 March 2012 / Published: 26 March 2012

\begin{abstract}
Nowadays microwave radiation is being researched to produce biodiesel from different raw materials due to the many advantages that this technology presents compared to traditional transesterification, such as shorter reaction times and less amount of heat energy to obtain biodiesel. The aim of this research was to explore the possibility of carrying out the microwave-assisted transesterification of macroalgae and compare the results with the traditional transesterification. For that reason, some experiences were conducted using sunflower oil and macroalgae as raw material. Based on the obtained results, the best conditions for microwave-assisted transesterification reaction were macroalgae to methanol ratio of 1:15 (wt/vol), sodium hydroxide concentration of $2 \mathrm{wt} \%$ and reaction time of $3 \mathrm{~min}$.
\end{abstract}

Keywords: macroalgae; sunflower oil; microwave-assisted transesterification; Chondrus crispus, Himanthalia elongata; Undaris pinnatifida

\section{Introduction}

Biodiesel is a diesel-equivalent biofuel made from renewable biological materials such as vegetable oils or animal fats. This biofuel has gained importance as an alternative energy source due to different reasons: the increase in the petroleum price and the necessity to decrease the pollution causes by the combustion of conventional diesel. Moreover, biodiesel has environmental advantages, such as low 
levels of carbon dioxide and monoxide emissions, low toxicity and it is biodegradable [1]. Its main characteristic is that biodiesel has similar propertied to conventional diesel, such as viscosity, cetane number, energy content, etc. Furthermore, it is possible to blend in any proportion with petroleum-derived diesel. For these reasons, biodiesel is one of the most common biofuels in the world.

Biodiesel, which is a mixture of fatty acid methyl esters (FAME), can be obtained by four methods: transesterification, pyrolysis, microemulsions and direct use and blending of raw oils [2]. Direct use is not suitable due to the high viscosity and low volatility of vegetable oils and animal fats. Pyrolysis, defined as the cleavage to smaller molecules by thermal energy, of vegetable oils over catalysts has been investigated [3,4]. However, it is a complicated process and produce side products without commercial value. Microemulsions with alcohols have been prepared to overcome the problem of high viscosity of vegetable oils. The most commonly used method is transesterification reaction in presence of a catalyst.

Transesterification is the reaction of an oil with an alcohol to obtain esters and glycerol. This reaction can be carried out in absence or presence of a catalyst. It is a reversible reaction, thus it is necessary to use an excess of alcohol to shift the equilibrium to the product side. The reaction occurs in three steps: (1) the conversion of triglycerides of diglycerides; (2) the conversion of higher glycerides to lower glycerides; (3) the conversion to glycerol.

Vegetable oils or animal fats are the most used raw material for biodiesel production. However, recently other raw materials, such as plants (jatropha, castor, neem, karanja and pongamia), macroalgae or microalgae are being considered as a promising alternative and renewable source for biodiesel production [5]. But the cultivation of some alternative raw materials requires huge land. Due to this, the use of macroalgae for biodiesel production has certain advantages compared to other energy crops: (a) their higher photosynthetic activity with respect to terrestrial plants; (b) the easy adaptability to different growing conditions; (c) the possibility of growing either in fresh-waters or marine-waters, avoiding the use of land; (d) macroalgae can also produce valuable co-products such as pellets, omega-3 fatty acids and several metabolites of economic interest (vitamins, poly unsaturated fatty acids, etc.). Moreover, from an environmental point of view, the use of macroalgae as raw material for biodiesel production gives a solution to the treatment of a waste collected in the beaches.

In the algae biodiesel production process, it is necessary to extract the oil by crushing followed by solvent extraction. However, the use of solvent for extraction may involve expensive separation process. Recently, different authors have reported the biodiesel production via direct transesterification of raw oleaginous materials [6-8]. Direct transesterification can be carried out using homogeneous (acid or base) catalysts [9]. An alternative to direct transesterification is the microwave-assisted reaction [10]. Many authors [11,12] are investigating the use of microwave radiation on biodiesel production. These studies indicate that the use of microwave irradiation could reduce reaction times significantly as well as improve product yields under atmospheric conditions. It is due to the fact that microwave irradiation activates the smallest degree of variance of polar molecules and ions such as alcohol with the continuously changing magnetic field. The changing electrical field, which interacts with the molecular dipoles and charged ion, causes these molecules or ions to have a rapid rotation and heat, is generated due to molecular friction. For that, the preparation of biodiesel using microwave could offer a fast, easy route to this valuable biofuel with advantages of a short reaction time, a low 
oil/methanol ratio, an ease of operation, a drastic reduction in the quantity of by-products, and all with reduced energy consumption [13].

In the current work, the effect microwave irradiation on the direct base-catalyzed transesterification of dry algal biomass has been analyzed. Sunflower vegetable oil is used to establish the operation conditions. Three marine macroalgae (Chondrus crispus, Himanthalia elongata, Undaris pinnatifida) are used as solid raw material for direct base-catalyzed transesterification. Aditionally, the conventional transesterification method is compared with the microwave-assisted transesterification method.

\section{Theory of Transesterification}

\subsection{Basic Transesterification}

The transesterification reaction involves the replacement of the alkyl group of an ester by another through interaction of the ester and alcohol. Generally, this reaction is catalyzed by a base or an acid catalyst. The basic catalysts are the most common since the process is faster and the reaction conditions are moderated. Figure 1 shows the base catalysis mechanism for triglycerides using alkali hydroxide as catalyst [14]. The first step (1) is a catalytic reaction with alcohol, producing an alkoxide. The nucleophilic attack of the alkoxide to the carbonyl group of the triglyceride generates a tetrahedral intermediate compound (2) from which the alkyl ester is formed and the corresponding anion of triglyceride (3). Finally, the catalyst is deionized, resulting in the regeneration of the active compound (4), which allows that it can react with a new molecule of alcohol, beginning a new catalytic cycle. In the notation used, B is the base catalyst, R1, R2 and R3 are the carbonyl groups of fatty acids and R is the functional group of alcohol.

Figure 1. Mechanism of basic transesterification reaction.

$$
\mathrm{ROH}+\mathrm{B} \rightleftharpoons \mathrm{RO}^{-}+\mathrm{BH}^{+}
$$

(2)

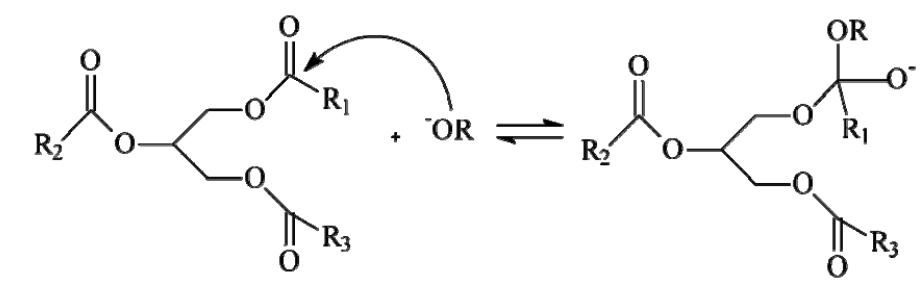

(3)

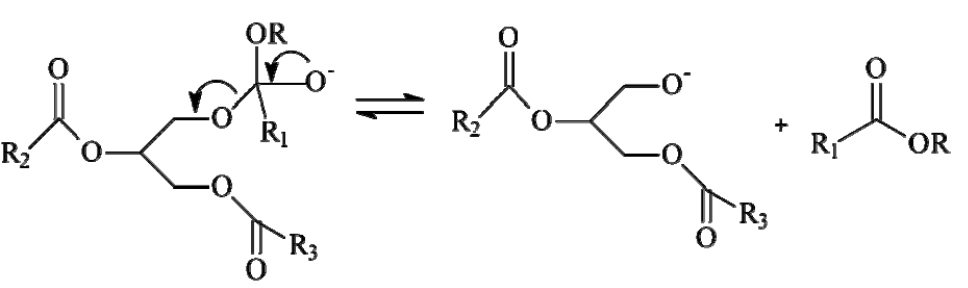

(4)<smiles>[R3]C(=O)OCC(C[O-])OC([R])=O</smiles> 


\subsection{Microwave Transesterification}

The mechanism of base-catalyzed microwave transesterification is shown in Figure 2. This mechanism involves three steps: (1) the attack of the alkoxide ion to the carbonyl carbon of the triglyceride molecule which results in the formation of a tetrahedral intermediate; (2) the alkoxide production by the reaction of the intermediate with an alcohol; (3) the rearrangement of the tetrahedral intermediate gives rise to an ester and a diglyceride. Similarly, diglyceride is transesterified to form methyl ester and monoglyceride is converted further to methyl ester and glycerol [15]. In the notation used, B is the base catalyst, R" is the glyceride, $\mathrm{R}^{\prime}$ is the carbon chain of fatty acid and $\mathrm{R}$ is the alkyl group of the alcohol.

Figure 2. Mechanism of microwave transesterification reaction.

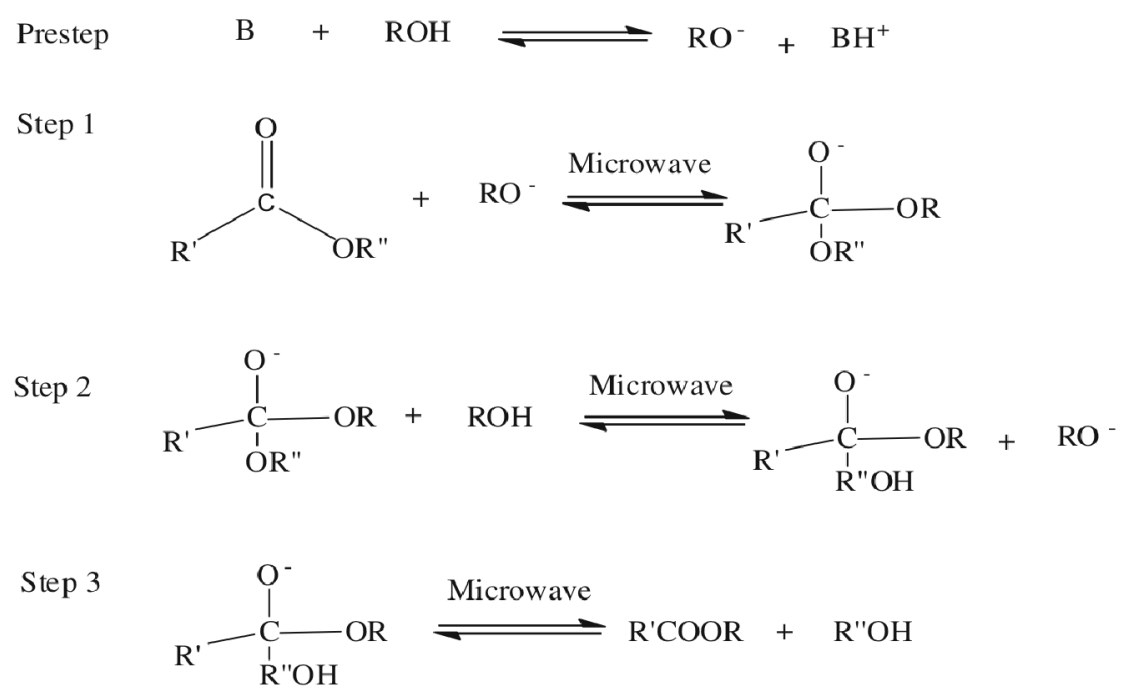

\section{Experimental Section}

\subsection{Characteristics of Algal Species}

Three marine macroalgae were used in this research: Chondrus crispus, Himanthalia elongata, Undaria pinnatifida. The major elements of these algae and their approximate composition are shown in Table 1.

Table 1. Major elements and composition (in wt \%) of three marine macroalgae.

\begin{tabular}{cccc}
\hline & Undaria pinnatifida & Himanthalia elongata & Chondrus crispus \\
\hline Fatty acids & 2.7 & 2.3 & 1.9 \\
Saturated fatty acids & 1.2 & 0.6 & 1.07 \\
Fiber & 31 & 36 & 43 \\
$\mathrm{Na}$ & 3.5 & 3.37 & 2.35 \\
$\mathrm{Ca}$ & 0.6932 & 0.6558 & 1.484 \\
$\mathrm{Mg}$ & 0.6302 & 0.7323 & 0.5722 \\
$\mathrm{P}$ & 0.470 & 0.230 & 0.200 \\
$\mathrm{Fe}$ & 0.00785 & 0.00407 & 0.0107 \\
$\mathrm{Zn}$ & 0.00386 & - & 0.004 \\
$\mathrm{I}$ & 0.009610 & 0.009240 & 0.000650 \\
\hline
\end{tabular}




\subsection{Experimental Procedure}

Once the different marine species of macroalgae found on the Galician coast have been characterized, the triglycerides transesterification from macroalgae oil can be carried out. The process selected for the transesterification is the alkaline catalysis transesterification. The novelty of this work is that the oil extraction step before the reaction is eliminated, since both extraction and reaction of the macroalgae oil are performed simultaneously in the reactor by means of in situ transesterification by traditional method and by microwave method. The schematic diagram of the process is shown in Figure 3.

The experiments were carried out using sunflower oil and macroalgae as raw material. In this research, the objective was compared both methods, by determined optimal conditions of transterification using microwave irradiation. In any cases, the objective of this research was not to obtain biodiesel.

First, comparative experiences of sunflower oil transesterification using both methods were carried out. In both methods, a molar ratio of oil to methanol of 1:6 and a catalyst concentration of 1 wt \% were used. The basic transesterification, was conducted at $60{ }^{\circ} \mathrm{C}$ for $5 \mathrm{~h}$ with constant stirring. For the microwave transesterification, the sunflower oil was subjected to the microwave irradiation using a domestic oven with a power of $800 \mathrm{~W}$ under different reaction times of 1, 3 and 6 min.

Then, the transesterification of macroalgae was carried out. For the basic transesterification, the dry macroalgae were mixed with methanol and introduced in a thermostated reactor. Two dry macroalgae to methanol (wt/vol) ratios were used: $1: 12$ and 1:15 and a catalyst concentration of $2 \mathrm{wt} \%$. Reaction was conducted at $60{ }^{\circ} \mathrm{C}$ for $5 \mathrm{~h}$ with constant stirring. For the microwave transesterification, the solid macroalgae was subjected to the microwave irradiation with a power of $800 \mathrm{~W}$ under a matrix of conditions: reaction times of 1, 3 and $6 \mathrm{~min}$; dry macroalgae to methanol (wt/vol) ratios 1:12 and 1:15; and catalyst concentration of $2 \mathrm{wt} \%$.

Figure 3. Schematic diagram of the process.

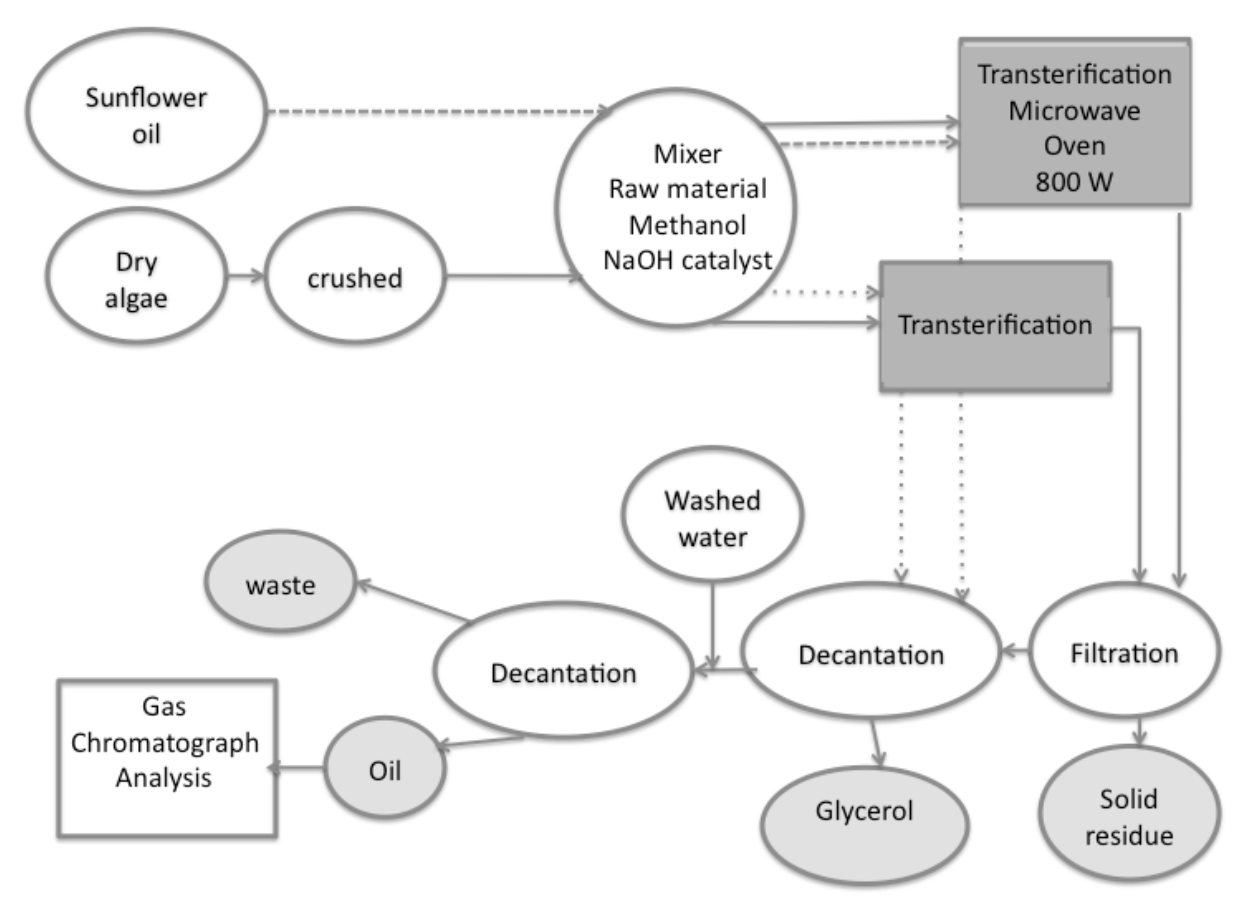


After the reaction, the mixture was cooled to room temperature. In the case of macroalge, the solid phase was separated by filtration using a Buchner funnel under vacuum. Then, the liquid phases were separated using a decantation funnel. Then, the upper organic layer was washed twice with hot water (20 mL). Finally, the fatty acid methyl esters (FAME) composition was analyzed by gas chromatography [5].

\section{Results and Discussion}

The main objective of this research was to explore the possibility of conducting the transesterification of macroalgae using the microwave radiation. In order to check the reproducibility of basic transesterification using microwave transesterification, experiences were conducted using sunflower oil as raw material. After accomplishing this step, the transesterification of macroalgae was carried out for both methods with the aim to compare the obtained results.

\subsection{Comparison of Transesterification Methods}

Sunflower was used to compare both methods since this reaction is widely studied and simplified the process due to the fact that it is a liquid raw material. The comparison of transesterification methods: basic and microwave irradiation is shown in Figure 4. It can be observed that using microwave transesterification during 3 min shows similar results that the traditional transesterification during $5 \mathrm{~h}$. These results reveal the importance of microwave irradiation in accelerating the transesterification reaction.

Figure 4. FAME yield of the sunflower oil using both methods.

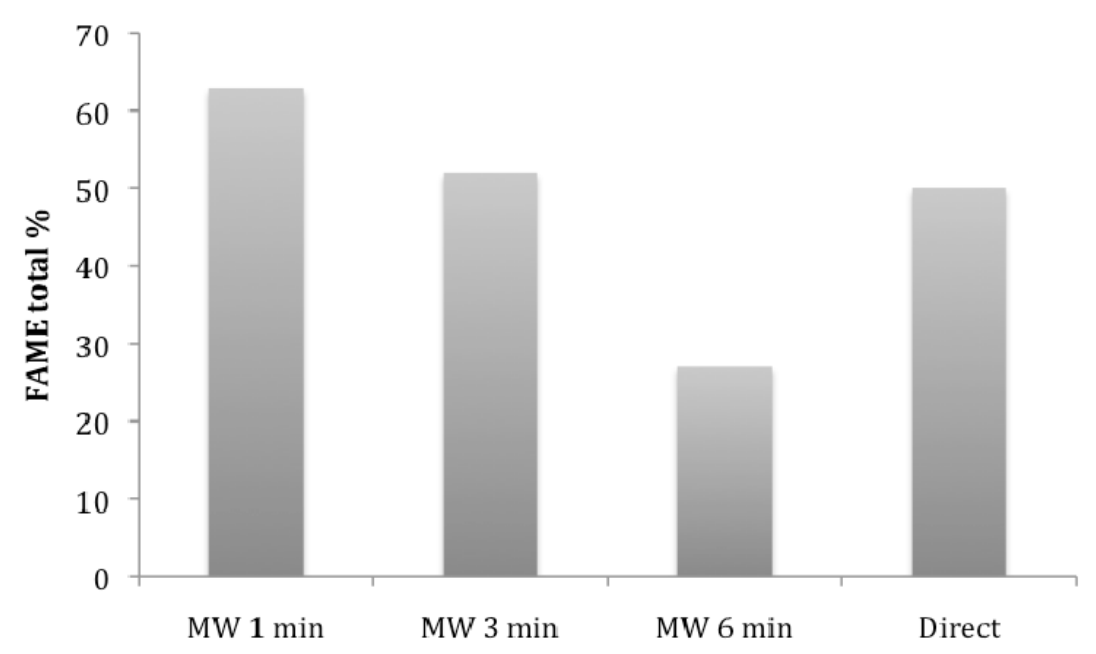

Comparing the obtained results using microwave irradiation, it can be said that the best FAME yield is obtained for $1 \mathrm{~min}$. If the reaction time is increased, a decrease in FAME yield is observed. The most accepted interpretation of this result is that the exceeded time favours the equilibrium in the reverse direction. This finding was also observed by other authors [16]. These authors attributing this decrease in yield after exceeding the optimum time to cracking followed by oxidizing of the formed fatty acid methyl esters to aldehydes, ketones and lower chained organic fractions but this phenomenon could be excluded because the GC results do not show peaks of oxygenated compounds [16]. The 
macroalgae oil oxidation produces a series of breakdown in stages, starting with primary oxidation products (free fatty acids), then secondary oxidation (aldehydes, ketones) and finally tertiary oxidation. In our study, due to the reduced reaction time, only primary and secondary oxidation may have been reached.

Considering the obtained results, the macroalgae transesterification using microwave radiation was carried out at 1 and $3 \mathrm{~min}$. The value of 6 min was rejected since the FAME \% presented the lowest value.

\subsection{Transesterification of Macroalgae}

Different test were carried out to analyze the effect of different process parameters namely algae to methanol (wt/vol) ratio and reaction time using microwave irradiation on the FAME content. Moreover, these results were also compared with the traditional transesterification.

Figure 5 shows the tendency of the obtained results for three macroalgae when the reaction time is varied in simultaneous extraction and transesterification. The reaction time has significant effect on the FAME content. The fact of using macroalgae as raw material requires higher reaction times [17], since it is necessary provide sufficient interaction of the reactant mixture to carry out the extraction and transesterification reaction.

Figure 5. Effect of reaction time.

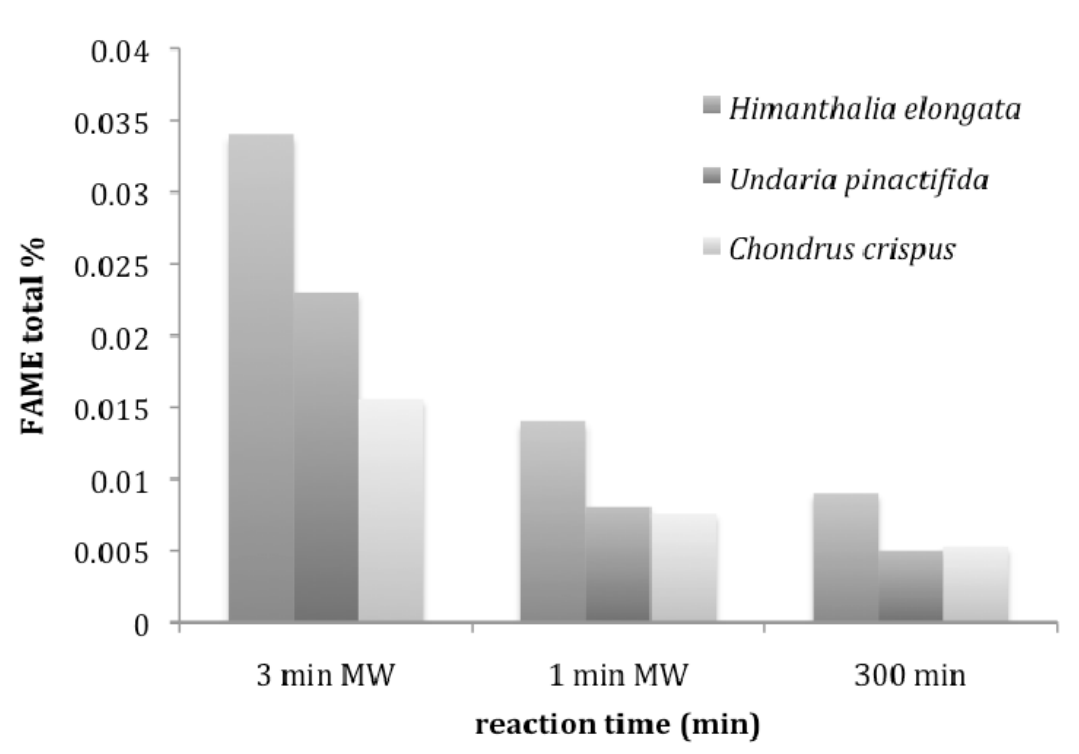

It can be concluded that using microwave transesterification implies a time saving process ( $3 \mathrm{~min}$ against $300 \mathrm{~min}$ ) since the best reaction time is for microwave irradiation at $3 \mathrm{~min}$. This result is different to the previous obtained for the sunflower oil where the higher FAME \% was obtained at 1 min. It must be taken into account that the sunflower oil is a liquid raw material while the macroalgae is solid. Therefore, lower reaction times do not provide sufficient interaction of the reactant mixture as the microwave effect is twofold in the extraction and transesterification reaction. Thermal effect caused by the microwaves increases the extractive properties of methanol to extract the oils from the algal biomass in suspension (diffusive extraction) and extended microwave effect causes the penetration through the cell walls and forces out the oils into the solvent mixture (disruptive 
extraction). Furthermore, it can be observed in Figure 5 that the lowest FAME content is obtained for the Chondrus crisprus. The justification of this finding could be that this macroalgae is harder and more fibrous.

Figure 6 shows the effect of methanol on the microwave transesterification $(3 \mathrm{~min})$ is significant with increasing macroalgae to methanol ratios for three macroalgae. It is observed that the FAME \% increases with the amount of methanol. Too low quantities of methanol are not suitable for the reaction as methanol is used in the reaction both as a solvent and a reactant. Hence, sufficient amount of methanol ratio is required to further drive the transesterification reaction which is determined to be 1:15 (wt/vol). The necessity of this excess of methanol is due to the methanol acts both as a solvent for extraction of the algal oils/lipids [18] as well as the reactant for transesterification of esters. When microwave radiation is used, methanol absorbs microwave radiation. It is due to the fact that its dipole quickly is reorientated in those conditions. This provokes the destroyment of structure of interface of methanol and oil extracted from the macroalgae [19]. For this reason, the solubility of methanol and algal oil is improved under microwave irradiation, to the advantage of the transesterification reaction [18].

Figure 6. Effect of macroalgae to methanol ratio (wt/vol).

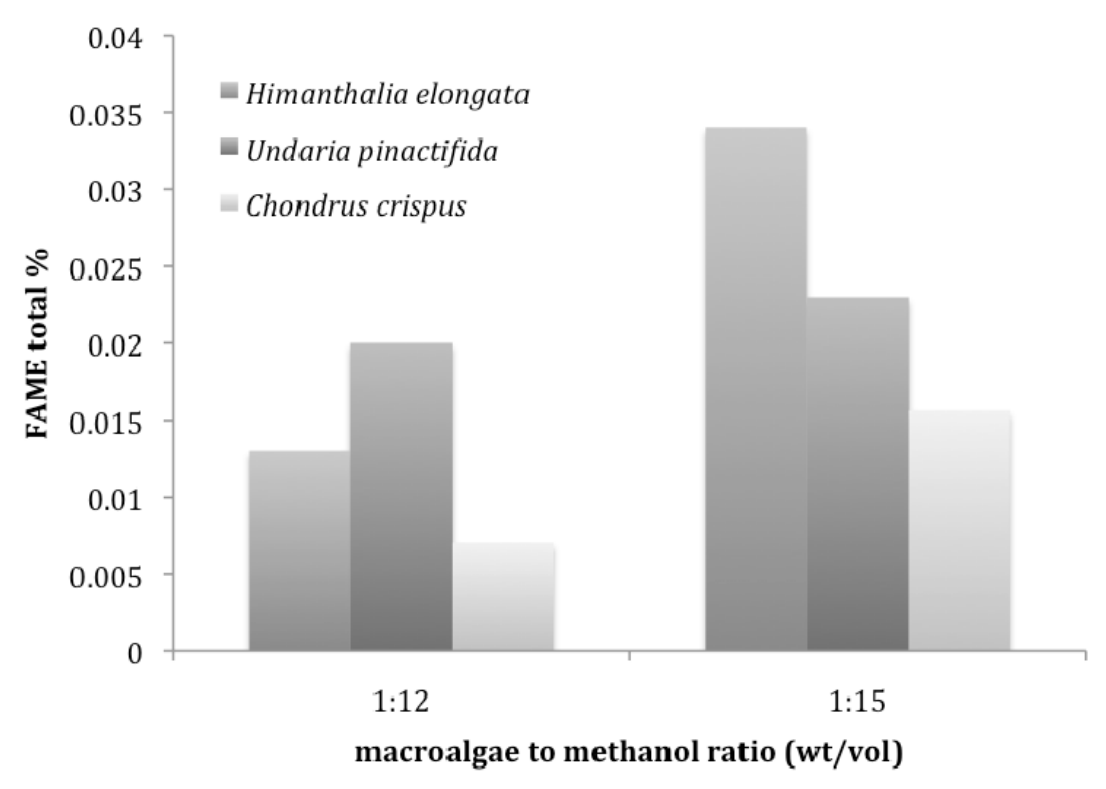

\section{Conclusions}

The transesterification using microwave irradiation reduces significantly the reaction time. Moreover, the reaction time depends on the type of raw material both microwave and traditional transesterification. From this research, it can be concluded that the best process conditions for microwave-assisted transesterification reaction are: macroalgae to methanol ratio of 1:15 (wt/vol), $\mathrm{NaOH}$ concentration of $2 \mathrm{wt} \%$ and the reaction time of $3 \mathrm{~min}$. Future work must be performed to optimize the biodiesel yield and analyze the percentage conversion from acyl-glycerides to free fatty acid. 


\section{References}

1. Mustafa, B. Potential alternatives to edible oils for biodiesel production-A review of current work. Energy Convers. Manag. 2011, 52, 1479-1492.

2. Siddiquee, M.N.; Rohani, S. Lipid extraction and biodiesel production from municipal sewage suldges: A review. Renew. Sustain. Energy Rev. 2011, 5, 1067-1072.

3. Balat, M. Production of biodiesel from vegetable oils: A survey. Energy Source Part A 2007, 29, 895-913.

4. Giridhar, M.; Chandana, K.; Rajnish, K. Synthesis of biodiesel in supercritical fluids. Fuel 2004, 83, 2029-2033.

5. Maceiras, R.; Rodríguez, M.; Cancela, M.A.; Urréjola, S.; Sánchez, A. Macroalgae: Raw material for biodiesel production. Appl. Energy 2011, 88, 3318-3323.

6. Johnson, M.B.; Wen, Z. Production of biodiesel fuel from the microalga Schizochytrium limacinum by direct transesterification of algal biomass. Energy Fuels 2009, 23, 5179-5183.

7. Liu, B.; Zhao, Z. Biodiesel production by direct methanolysis of oleaginous microbial biomass. J. Chem. Technol. Biotechnol. 2007, 82, 775-780.

8. Maceiras, R.; Cancela, A.; Urréjola, S.; Sánchez, A.; Pérez L. Development of renewable fuels from algae. In Proceedings of European Meeting on Chemical Industry and Environment, Mechelen, Belgium, 17-19 May 2010; pp. 501-508.

9. Ross, A.B.; Biler, P.; Kubacki, M.L.; Li, H.; Lea-Langton, A.; Jones, J.M. Hydrothermal processing of microalgae using alkali and organic acids. Fuel 2010, 89, 2234-2243.

10. Nezihe, A.; Aysegul, D. Alkali catalyzed transesterification of cottonseed oil by microwave irradiation. Fuel 2007, 86, 2639-2644.

11. Yaakob, Z.; Ong, B.H.; Kumar, M.N.S.; Kamarudin, S.K. Microwave-assisted transesterification of jatropha and waste frying palm oil. Int. J. Sustain. Energy 2009, 28, 195-201.

12. Yu, D.; Tian, L.; Ma, D.; Wu, H.; Wang, Z.; Wang, L.; Fang, X. Microwave-assisted fatty acid methyl ester production from soybean oil by Novozym 435. Green Chem. 2010, 12, 844-850.

13. Vyas, A.P.; Verma, J.L.; Subrahmanyam, N. A review on FAME production processes. Fuel 2010, 89, 1-9.

14. Lotero, E.; Liu, Y.; López, D.E.; Suwannakarn, K.; Bruce, D.A.; Goodwin, J.G. Synthesis of biodiesel via acid catalysis. Ind. Eng. Chem. Res. 2005, 44, 5353-5363.

15. Patil, P.D.; Gnaneswar, V.; Mannarswamy, A.; Cooke, P.; Munson-McGee, S.; Nirmalakhandan, N.; Lammers, P.; Deng, S. Optimization of microwave-assisted transesterification of dry algal biomass using response surface methodology. Bioresource Technol. 2011, 102, 1399-1405.

16. Refaat, A.A.; El Sheltawy, S.T.; Sadek, K.U. Optimum reaction time, performance and exhaust emissions of biodiesel produced by microwave irradiation. Int. J. Environ. Sci. Technol. 2008, 5, 315-322.

17. Sánchez, A.; Maceiras, R.; Cancela, A.; Rodríguez, M. Influence of $n$-hexane on in situ transesterification of marine macroalgae. Energies 2012, 5, 243-257.

18. Mulbry, W.; Kondrad, S.; Buyer, J.; Luthria, D. Optimization of an oil extraction process for algae from the treatment of manure effluent. J. Am. Oil Chem. Soc. 2009, 86, 909-915. 
19. Yuan, H.; Yang, B.L.; Zhu, G.L. Synthesis of biodiesel using microwave absorption catalysts. Energy Fuels 2009, 23, 548-552.

(C) 2012 by the authors; licensee MDPI, Basel, Switzerland. This article is an open access article distributed under the terms and conditions of the Creative Commons Attribution license (http://creativecommons.org/licenses/by/3.0/). 